\title{
Los antibióticos ß lactámicos son efectivos en el tratamiento empírico inicial de la neumonía aguda de la comunidad
}

\section{Objetivo}

Generar evidencia clase I para guiar las recomendaciones terapéuticas en la neumonía aguda de la comunidad (NAC) leve a moderada, así como disipar las controversias existentes en lo que respecta a la terapéutica antibiótica empírica inicial y la cobertura o no de gérmenes atípicos.

\section{Fuentes de Datos}

Registro Central de Ensayos Controlados de Cochrane, Medline y Embase. Se buscó asimismo en las listas de referencias secundarias y se contactaron las compañías farmacéuticas que realizaron ensayos clínicos sobre el tópico.

\section{Selección de Estudios}

Se seleccionaron ensayos clínicos controlados, aleatorizados, doble ciego, comparando monoterapia de antibióticos activos hacia gérmenes atípicos (fluoroquinolonas, macrólidos) contra $B$ Lactámicos (Penicilinas y Cefalosporinas). Se excluyeron trabajos que hicieran referencia a neumonía nosocomial o aspirativa, pacientes inmunocomprometidos o con importante comorbilidad. $E$ punto final primario* fue la falla en lograr mejoría o cura clínica evaluada inmediatamente de finalizado el tratamiento.

\section{Extracción de Datos}

Se incluyeron 18 ensayos clínicos (1980-2000) en más de 30 países, con una población total de 6749 pacientes. Las edades promedio oscilaron entre 40-60 años. Se compararon fluoroquinolonas (ciprofloxacina, gatifloxacina, gemifloxacina, grepafloxacina, levofloxacina, moxifloxacina, sparfloxacina, temifloxacina, trovafloxacina), macrólidos (eritromicina, azitromicina), un ketólido (telitromicina), contra cuatro B lactámicos (cefaclor, ceftriaxona, ampicilina, amoxicilina, asociados o no a acido clavulánico). La va loración del punto final se realizó en forma inmediata (días) a la finalización del tratamiento. Todos los estudios reportaron la tasa de fallo terapéutico. La gran mayoría de los estudios fueron analizados por intención de tratar*.

\section{Resultados Principales}

No se encontró diferencia significativa en la tasa de fracaso terapéutico entre los distintos antibióticos en relación a los ß lactámicos, ni analizados globalmente o por familia (ver tabla). No se detectó heterogeneidad. * La mortalidad global estuvo acorde a la esperada para neumonías de manejo ambulatorio (1.9\%), sin observarse diferencias en las ramas (RR 1,20; IC95\% 0,84-1,71). En total se diagnosticaron 311 casos de neumonía por Mycoplasma, 115 por Clamidia y 75 por Legionella. Al realizar análisis de subgrupos por gérmenes atípicos tratados, tampoco hubo diferencias significativas de falla para Mycoplasma (RR 0,60; IC95\% 0,31-1,17) ni Clamidia (RR 2,32; IC95\% 0,67-8,03), pero sí para Legionella (RR 0,4; IC95\% 0,19-0,85).

Tabla: Riesgo de fallo terapéutico de antibióticos para NAC vs B lactámicos

\begin{tabular}{l|l|l|l}
\hline Antibiótico & RR & IC 95\% & p \\
\hline Macrólidos & 0,81 & $0,58-1,14$ & NS \\
\hline Quinolonas & 0,99 & $0,88-1,11$ & NS \\
\hline Total & 0,97 & $0,87-1,07$ & NS \\
\hline
\end{tabular}

\section{Conclusiones}

El presente articulo avala el tratamiento empírico inicial de las neumonías agudas de la comunidad de manejo ambulatorio (leves a moderadas) con antibióticos B Lactámicos como primera opción terapéutica, independientemente del germen sospechado.

Fuente de financiamiento: financiamiento parcial de la dirección de Salud del distrito de Waikato, Nueva Zelandia.

\section{Comentario}

Desde el punto de vista clínico-radiológico la NAC puede clasificarse como típica o atípica, haciendo referencia estas últimas a aquellas producto de la infección por gérmenes resistentes in vitro a la acción de los antibióticos B Lactámicos (Mycoplasma, Clamidia, legionella, virus entre otros).

Resulta habitual en la práctica médica que la elección del tratamiento empírico inicial de un cuadro respiratorio neumónico sea influenciada por un determinado patrón radiológico, la evolución clínica, o por recomendaciones de guías de práctica clínica basadas en la epidemiología de los distintos agentes microbiológicos.

La dificultad en obtener confirmación etiológica oportuna (sea por la baja sensibilidad de los métodos disponibles o por el tiempo necesario en la interpretación de datos), la falta de precisión de la clínica y la radiología para predecir los gérmenes involucrados, y la demostración de que aún neumonías en las que se documentaron agentes atípicos responden favorablemente a tratamiento antibiótico no especifico como los B Lactámicos, ponen en duda la relevancia de las llamadas neumonías atípicas en la práctica ambulatoria. En cuanto a las distintas guías de práctica actualmente vigentes existe disparidad de recomendaciones. Por un lado, la American Thoracic Society, la Infectious Disease Society of America y la Canadian Infectious Disease Society proponen el tratamiento de pacientes ambulatorios sin comorbilidad con macrólidos o doxicicli- na como primera opción terapéutica, dejando el uso de $B$ lactámicos (generalmente asociados a inhibidores de $B$ lactamasa $u$ otros antibióticos) y quinolonas respiratorias como segunda opción, sobre todo para aquellos pacientes con comorbilidades 1 .

Por otro lado, la British Thoracic Society propone el uso de $B$ lactámicos (amoxicilina) en la misma línea inicial junto a los macrólidos para el tratamiento empírico inicial de la NAC ${ }^{1}$. En la Argentina esta recomendación también es compartida por una guía de práctica clínica Inter - sociedades².

\section{Conclusiones del comentador}

El presente metaanálisis apoya con evidencia de buena calidad el uso de $B$ lactámicos para el tratamiento empírico inicial de la NAC leve a moderada. Si bien no se analizó la costo-efectividad de los diferentes esquemas terapéuticos, ni se confrontaron diferentes $\beta$ lactámicos entre sí, resulta atractivo para nuestro medio la opción de tratamiento inicial con amoxicilina para las NAC en pacientes de bajo riesgo, reservando así los macrólidos, tetraciclinas y quinolonas (generalmente más costosos) como alternativa en aquellos que luego de 48-72 hs no logran mejoría clínica o en aquellos pacientes alérgicos a la penicilina.

\section{Dr. Gabriel Villalón [ Unidad de Medicina Familiar y Preventiva. Hospital Italiano de Buenos Aires. ]}

Villalón, G. Los antibióticos B lactámicos son efectivos en el tratamiento empírico inicial de la neumonia aguda de la comunidad Evid. actual. práct. ambul. 2005;8:104. Comentado de: Mills GD, Oehley MR, Arrol B. Effectiveness of B lactam antibiotics compared with antibiotics active against atypical pathogens in non-severe comunity acquired pneumonia: meta-analisis. BMJ 2005;330:456-60. PMID: 15684024

Referencias

1. Adelson J, Zaleznik D. Treatment of community-acquired pneumonia. In: Uptodate, Vol 12 N3.

2. Luna CM, Efrom ED, Schiavi y cols. Neumonía adquirida en la comunidad en adultos. Guía práctica clínica para la Argentina. Medicina 2003;63:319-343. 